\title{
Communication
}

\section{Ligand Binding Affinities of Arctigenin and Its Demethylated Metabolites to Estrogen Receptor Alpha}

\author{
Jong-Sik Jin ${ }^{1}$, Jong-Hyun Lee ${ }^{2}$ and Masao Hattori ${ }^{1}{ }^{1} *$ \\ 1 Institute of Natural Medicine, University of Toyama, 2630 Sugitani, Toyama 930-0194, Japan \\ 2 College of Pharmacy, Dongduk Women's University, 23-1 Wolgok-Dong, Sungbuk-Gu, \\ Seoul 136-714, Korea \\ * Author to whom correspondence should be addressed; E-Mail: mhattori@po4.canet.ne.jp; \\ Tel./Fax: +81-766-52-4314.
}

Received: 8 October 2012; in revised form: 10 January 2013 / Accepted: 14 January 2013 / Published: 16 January 2013

\begin{abstract}
Phytoestrogens are defined as plant-derived compounds with estrogen-like activities according to their chemical structures and activities. Plant lignans are generally categorized as phytoestrogens. It was reported that (-)-arctigenin, the aglycone of arctiin, was demethylated to (-)-dihydroxyenterolactone (DHENL) by Eubacterium (E.) sp. ARC-2. Through stepwise demethylation, E. sp. ARC-2 produced six intermediates, three monodesmethylarctigenins and three di-desmethylarctigenins. In the present study, ligand binding affinities of (-)-arctigenin and its seven metabolites, including DHENL, were investigated for an estrogen receptor alpha, and found that demethylated metabolites had stronger binding affinities than (-)-arctigenin using a ligand binding screen assay method. The $\mathrm{IC}_{50}$ value of $(2 R, 3 R)$-2-(4-hydroxy-3-methoxybenzyl)-3-(3,4-dihydroxybenzyl)butyrolactone was $7.9 \times 10^{-4} \mathrm{M}$.
\end{abstract}

Keywords: arctigenin; estrogen receptor alpha; demethylation; ligand binding affinity

\section{Introduction}

Some plant lignans have been categorized as phytoestrogens or their precursors with isoflavones because natural compounds and/or their metabolites act like estrogen [1-3]. Estrogenic and anti-estrogenic activities of phytoestrogens have been studied for a long time and potential hormone-like effects were assumed [4-6]. The dietary lignans such as secoisolariciresinol diglucoside, pinoresinol diglucoside, 
sesamin, asarinin, tracheloside and arctiin are transformed to mammalian lignans, enterolactone (ENL) and enterodiol (END) by human intestinal bacteria [3,7-11]. Many human intestinal bacteria having metabolic activities are involved in the biotransformation [7,8,12-20]. As a result, the bacterial metabolism not only produces END and ENL, mammalian lignans, but also diverse metabolites.

Six metabolites are produced by incubation of arctiin, abundant in the seeds of Arctium (A.) lappa, with human intestinal bacteria [10]. The metabolic processes include deglucosylation, demethylation, and dehydroxylation. Since arctiin has three methoxy groups in aromatic rings and demethylation occurs prior to dehydroxylation [8], this showed that the demethylation process is quite important for producing enterolactone.

Eubacterium (E.) limosum ARC-2 is isolated as a human intestinal bacterium, capable of demethylating arctigenin from human feces [20]. (-)-Acrtigenin (8) is metabolized to $(-)$-dihydroxyenterolactone (DHENL, 1) through stepwise demethylation. Six intermediates 2-7 are isolated, as shown in the previous paper (Figure 1).

Figure 1. Arctigenin and its metabolites by E. sp. ARC-2.<smiles>[R20]Oc1ccc(C[C@@H]2COC(=O)C2Cc2ccc(O)c([R20])c2)cc1O</smiles>

\begin{tabular}{clll} 
Compound & \multicolumn{1}{c}{$\mathbf{R}_{\mathbf{1}}$} & \multicolumn{1}{c}{$\mathbf{R}_{\mathbf{2}}$} & \multicolumn{1}{c}{$\mathbf{R}_{\mathbf{3}}$} \\
$\mathbf{1}$ & $-\mathrm{H}$ & $-\mathrm{H}$ & $-\mathrm{H}$ \\
$\mathbf{2}$ & $-\mathrm{H}$ & $-\mathrm{H}$ & $-\mathrm{CH}_{3}$ \\
$\mathbf{3}$ & $-\mathrm{CH}_{3}$ & $-\mathrm{H}$ & $-\mathrm{H}$ \\
$\mathbf{4}$ & $-\mathrm{H}$ & $-\mathrm{CH}_{3}$ & $-\mathrm{H}$ \\
$\mathbf{5}$ & $-\mathrm{CH}_{3}$ & $-\mathrm{H}$ & $-\mathrm{CH}_{3}$ \\
$\mathbf{6}$ & $-\mathrm{CH}_{3}$ & $-\mathrm{CH}_{3}$ & $-\mathrm{H}$ \\
$\mathbf{7}$ & $-\mathrm{H}$ & $-\mathrm{CH}_{3}$ & $-\mathrm{CH}_{3}$ \\
$\mathbf{8}$ & $-\mathrm{CH}_{3}$ & $-\mathrm{CH}_{3}$ & $-\mathrm{CH}_{3}$
\end{tabular}

In present study, we examined the binding affinity of (-)-arctigenin (8) and its metabolites 1-7 using an estrogen receptor alpha (ERalpha) competitor screening assay.

\section{Results and Discussion}

The half maximal inhibitory concentration $\left(\mathrm{IC}_{50}\right)$ value of $(-)$-arctigenin $(\mathbf{8})$ was higher than $5 \times 10^{-3} \mathrm{M}$ (Table 1). Out of three mono-desmethylarctigenins 5-7, including (-)-matairesinol (5), the $\mathrm{IC}_{50}$ value of metabolite 6 was $2.5 \times 10^{-3} \mathrm{M}$, being lower that that of the original compound $\mathbf{8}$. This finding agreed with a previous observation by Xie et al., who showed metabolite 6 stimulated the proliferation of MCF-7 human breast cancer cells, having estradiol-mediated proliferative characteristics [10]. 
Metabolite $\mathbf{6}$ is a main metabolite in incubation of arctiin with human and rat intestinal flora in vitro [10,21]. However, when arctigenin (8) was incubated with E. limosum ARC-2, the major monodesmethylarctigenin was metabolite 7 [20]. It means that the composition of human intestinal microbiota could change the metabolic pattern of arctigenin $(\mathbf{8})$, followed by alteration of estrogenic activity.

Table 1. Ligand binding affinities of arctigenin and its metabolites to ER alpha.

\begin{tabular}{ccccccc}
\hline \multirow{2}{*}{ Compound } & \multicolumn{5}{c}{ \% Binding to ER $\boldsymbol{\alpha}$} & \multirow{2}{*}{ IC } \\
\cline { 2 - 5 } & $10^{-5} \mathrm{M}$ & $10^{-4} \mathrm{M}$ & $5 \times 10^{-4} \mathrm{M}$ & $5 \times 10^{-3} \mathrm{M}$ & \multirow{2}{*}{ RBA } \\
\hline $\mathbf{1}$ & $5.6 \pm 3.3^{*}$ & $13.7 \pm 0.7 * *$ & $34.8 \pm 1.3 * *$ & $65.3 \pm 0.2 * *$ & $1.6 \times 10^{-3} \mathrm{M}$ & $1.2 \times 10^{-3}$ \\
$\mathbf{2}$ & $1.4 \pm 1.2$ & $13.5 \pm 2.0 * *$ & $44.4 \pm 0.9 * *$ & $67.7 \pm 0.2 * *$ & $7.9 \times 10^{-4} \mathrm{M}$ & $2.5 \times 10^{-3}$ \\
$\mathbf{3}$ & $2.2 \pm 1.6$ & $14.1 \pm 1.3 * *$ & $25.8 \pm 0.8 * *$ & $67.5 \pm 0.2 * *$ & $1.9 \times 10^{-3} \mathrm{M}$ & $1.0 \times 10^{-3}$ \\
$\mathbf{4}$ & $1.0 \pm 1.4$ & $-0.5 \pm 0.7$ & $19.6 \pm 2.3 * *$ & $63.2 \pm 0.3 * *$ & $2.5 \times 10^{-3} \mathrm{M}$ & $7.9 \times 10^{-4}$ \\
$\mathbf{5}$ & $0.4 \pm 0.9$ & $18.1 \pm 9.0 * *$ & $0.1 \pm 2.6$ & $17.6 \pm 1.1 * *$ & $>5 \times 10^{-3} \mathrm{M}$ & - \\
$\mathbf{6}$ & $-2.3 \pm 0.9$ & $1.4 \pm 2.4$ & $16.6 \pm 0.9 * *$ & $64.5 \pm 0.2 * *$ & $2.5 \times 10^{-3} \mathrm{M}$ & $7.9 \times 10^{-4}$ \\
$\mathbf{7}$ & $3.6 \pm 0.6$ & $1.2 \pm 1.7$ & $-4.2 \pm 0.8$ & $30.1 \pm 1.7 * *$ & $>5 \times 10^{-3} \mathrm{M}$ & - \\
$\mathbf{8}$ & $-1.4 \pm 0.8$ & $-4.3 \pm 0.8$ & $-4.1 \pm 3.5$ & $19.4 \pm 1.5 * *$ & $>5 \times 10^{-3} \mathrm{M}$ & - \\
\hline
\end{tabular}

Estradiol $\mathrm{IC}_{50}=1.99 \times 10^{-8} \mathrm{M}$. RBA (Relative binding affinity) was calculated by dividing the $\mathrm{IC}_{50}$ of estradiol by that of the tested compound and multiplied by 100 , Estradiol $(\mathrm{RBA}=100)$. Asterisks denotes significant difference from the control at $(*) p<0.05,(* *) p<0.01(n=4)$.

Metabolites 2, 3, and 4, three di-desmethylarctigenins, showed $\mathrm{IC}_{50}$ values of $7.9 \times 10^{-4} \mathrm{M}, 1.9 \times 10^{-3} \mathrm{M}$, and $2.5 \times 10^{-3} \mathrm{M}$, respectively. The $\mathrm{IC}_{50}$ values of the end metabolite, (-)-DHENL (1) was $1.6 \times 10^{-3} \mathrm{M}$. Di-desmethylarctigenins showed rather strong binding affinities compared to mono-desmethylarctigenins. Similarly, in isoflavones, the demethylated metabolites showed stronger estrogen receptor affinity [22]. Remarkable changes in estrogen receptor affinity were observed between daidzein, genistein and their methylated compounds, formononetin and biochanin A.

It has been reported that a phenolic hydroxyl group is a prominent substructural feature for binding to ER and that the distance between two hydroxyl groups is an important factor [23,24]. However, due to the demethylation position, the distances between hydroxyl groups become different. Moreover, further dehydroxylation influences the number of hydroxyl groups and distances because a para hydroxyl group which has a vincinal hydroxyl group can be degraded [7].

Arctigenin (8) and its metabolites 1-7 showed relatively weak ligand binding affinities. However, it becomes clear that the structural differences between the series of these compounds affect the ligand binding affinities to ERalpha.

\section{Experimental}

\subsection{Chemicals}

(-)-Arctigenin (8) was isolated from the seeds of $A$. lappa and its metabolites 1-7 were prepared by anaerobic incubation of (-)-arctigenin (8) as previously reported [20]. 17 $\beta$-Estradiol was purchased from Calbiochem Co. (Darmstadt, Germany). 


\subsection{Ligand Binding Screen}

An estrogen-R $(\alpha)$ competitor screening kit was purchased from Wako Chemicals (Osaka, Japan). The assay depends on the competition between the samples applied in different concentrations and the labeled estrogen mixture. The amount of the ligand that binds to the ERalpha coated on the microplate well is determined by the dynamic equilibrium among all the ligand concentrations in the mixture, the difference of their binding affinities to the receptor, and the incubation time. Therefore, the reduction in fluorescence intensities from the labeled estrogen retained is an indication of the affinity of the added compounds to the estrogen receptor. (-)-Arctigenin (8) and its metabolites were tested in $10^{-5}$, $10^{-4}, 5 \times 10^{-4}$, and $5 \times 10^{-3} \mathrm{M}$ concentrations. Estradiol was used as a positive control and a labeled estrogen mixture was used as a negative control. The results were calculated as percentages of the negative control.

\subsection{Statistical Analysis}

Each set of experiments was repeated at least three times. Values are expressed as mean \pm S.E.M. One-way analysis of variance followed by Dunnett's test was used for statistical analysis. The $\mathrm{IC}_{50}$ was calculated using a non-linear regression analysis (for one site competition).

\section{Conclusions}

In this study, we examined the binding affinities of (-)-arctigenin and its seven demethylated metabolites by E. limosum ARC-2 to ERalpha. Though ligand binding affinities were weak compared to estradiol and estrogenic isoflavones, the result showed a tendency that demethylated metabolites are stronger binding ligands to the receptor.

\section{Conflicts of Interest}

The authors declare there are no conflicts of interest.

\section{References}

1. Bingham, S.A.; Atkinson, C.; Liggins, J.; Bluck, L.; Coward, A. Phyto-oestrogens: Where are we now? Br. J. Nutr. 1998, 79, 393-406.

2. Rowland, I.; Faughnan, M.; Hoey, L.; Wahala, K.; Williamson, G.; Cassidy, A. Bioavailability of phyto-oestrogens. Br. J. Nutr. 2003, 89, S45-S58.

3. Jin, J.S.; Tobo, T.; Chung, M.H.; Ma, C.M.; Hattori, M. Transformation of trachelogenin, an aglycone of tracheloside from safflower seeds, to phytoestrogenic (-)-enterolactone by human intestinal bacteria. Food Chem. 2012, 134, 74-80.

4. Adlercreutz, H.; Mousavi, Y.; Clark, J.; Hockerstedt, K.; Hamalainen, E.; Wahala, K.; Makela, T.; Hase, T. Dietary phytoestrogens and cancer: In vitro and in vivo studies. J. Steroid. Biochem. Mol. Biol. 1992, 41, 331-337. 
5. Mueller, S.O.; Simon, S.; Chae, K.; Metzler, M.; Korach, K.S. Phytoestrogens and their human metabolites show distinct agonistic and antagonistic properties on estrogen receptor alpha (ERalpha) and ERbeta in human cells. Toxicol. Sci. 2004, 80, 14-25.

6. Schottner, M.; Gansser, D.; Spiteller, G. Lignans from the roots of Urtica dioica and their metabolites bind to human sex hormone binding globulin (SHBG). Planta Med. 1997, 63, 529-532.

7. Xie, L.H.; Akao, T.; Hamasaki, K.; Deyama, T.; Hattori, M. Biotransformation of pinoresinol diglucoside to mammalian lignans by human intestinal microflora, and isolation of Enterococcus faecalis strain PDG-1 responsible for the transformation of (+)-pinoresinol to (+)-lariciresinol. Chem. Pharm. Bull. 2003, 51, 508-515.

8. Wang, L.Q.; Meselhy, M.R.; Li, Y.; Qin, G.W.; Hattori, M. Human intestinal bacteria capable of transforming secoisolariciresinol diglucoside to mammalian lignans, enterodiol and enterolactone. Chem. Pharm. Bull. 2000, 48, 1606-1610.

9. Penalvo, J.L.; Heinonen, S.M.; Aura, A.M.; Adlercreutz, H. Dietary sesamin is converted to enterolactone in humans. J. Nutr. 2005, 135, 1056-1062.

10. Xie, L.H.; Ahn, E.M.; Akao, T.; Abdel-Hafez, A.A.M.; Nakamura, N.; Hattori, M. Transformation of arctiin to estrogenic and antiestrogenic substances by human intestinal bacteria. Chem. Pharm. Bull. 2003, 51, 378-384.

11. Jin, J.S.; Hattori, M. A new mammalian lignan precursor, asarinin. Food Chem. 2011, 124, 895-899.

12. Jin, J.S.; Hattori, M. Human intestinal bacterium, strain END-2 is responsible for demethylation as well as lactonization during plant lignan metabolism. Biol. Pharm. Bull. 2010, 33, 1443-1447.

13. Jin, J.S.; Hattori, M. Further studies on a human intestinal bacterium Ruminococcus sp. END-1 for transformation of plant lignans to mammalian lignans. J. Agric. Food Chem. 2009, 57, 7537-7542.

14. Clavel, T.; Henderson, G.; Alpert, C.A.; Philippe, C.; Rigottier-Gois, L.; Doré, J.; Blaut, M. Intestinal bacterial communities that produce active estrogen-like compounds enterodiol and enterolactone in humans. Appl. Environ. Microbiol. 2005, 71, 6077-6085.

15. Clavel, T.; Henderson, G.; Engst, W.; Doré, J.; Blaut, M. Phylogeny of human intestinal bacteria that activate the dietary lignan secoisolariciresinol diglucoside. FEMS Microbiol. Ecol. 2006, 55, 471-478.

16. Clavel, T.; Borrmann, D.; Braune, A.; Doré, J.; Blaut, M. Occurrence and activity of human intestinal bacteria involved in the conversion of dietary lignans. Anaerobe 2006, 12, 140-147.

17. Clavel, T.; Lippman, R.; Gavini, F.; Doré, J.; Blaut, M. Clostridium saccharogumia sp. nov. and Lactonifactor longoviformis gen. nov., sp. nov., two novel human faecal bacteria involved in the conversion of the dietary phytoestrogen secoisolariciresinol diglucoside. Syst. Appl. Microbiol. 2007, 30, 16-26.

18. Jin, J.S.; Kakiuchi, N.; Hattori, M. Enantioselective oxidation of enterodiol to enterolactone by human intestinal bacteria. Biol. Pharm. Bull. 2007, 30, 2204-2206.

19. Jin, J.S.; Zhao, Y.F.; Nakamura, N.; Akao, T.; Kakiuchi, N.; Min, B.S.; Hattori, M. Enantioselective dehydroxylation of enterodiol and enterolactone precursors by human intestinal bacteria. Biol. Pharm. Bull. 2007, 30, 2113-2119. 
20. Jin, J.S.; Zhao, Y.F.; Nakamura, N.; Akao, T.; Kakiuchi, N.; Hattori, M. Isolation and characterization of a human intestinal bacterium, Eubacterium sp. ARC-2, capable of demethylating arctigenin, in the essential metabolic process to enterolactone. Biol. Pharm. Bull. 2007, 30, 904-911.

21. Nose, M.; Fujimoto, T.; Takeda, T.; Nishibe, S.; Ogihara, Y. Structural transformation of lignan compounds in rat gastrointestinal tract. Planta Med. 1992, 58, 520-523.

22. Pfitscher, A.; Reiter, E.; Jungbauer, A. Receptor binding and transactivation activities of red clover isoflavones and their metabolites. J. Steroid Biochem. Mol. Biol. 2008, 112, 87-94.

23. Klopman, G.; Chakravarti, S.K. Structure-activity relationship study of a diverse set of estrogen receptor ligands (I) using MultiCASE expert system. Chemosphere 2003, 51, 445-459.

24. Fang, H.; Tong, W.; Shi, L.M.; Blair, R.; Perkins, R.; Branham, W.; Hass, B.S.; Xie, Q.; Dial, S.L.; Moland, C.L.; Sheehan, D.M. Structure-activity relationships for a large diverse set of natural, synthetic, and environmental estrogens. Chem. Res. Toxicol. 2001, 14, 280-294.

Sample Availability: Samples of the compounds were isolated by authors. Not all the compounds are available.

(C) 2013 by the authors; licensee MDPI, Basel, Switzerland. This article is an open access article distributed under the terms and conditions of the Creative Commons Attribution license (http://creativecommons.org/licenses/by/3.0/). 